\title{
Resolution of Ibuprofen with Primary Amine Carbamates in Supercritical Carbon Dioxide
}

\author{
László Lőrincz¹, Zsolt Hovonyecz¹, János Madarász², Erzsébet Varga³, Edit Székely \\ 1 Department of Chemical and Environmental Process Engineering, Faculty of Chemical Technology and Biotechnology, \\ Budapest University of Technology and Economics, H-1111 Budapest, Budafoki út 6-8., Hungary \\ 2 Department of Inorganic and Analytical Chemistry, Faculty of Chemical Technology and Biotechnology, \\ Budapest University of Technology and Economics, H-1111 Budapest, Szent-Gellért tér 4., Hungary \\ ${ }^{3}$ Cyclolab Ltd., H-1111 Budapest, Illatos út 7., Hungary \\ *Corresponding author, e-mail: sz-edit@mail.bme.hu
}

Received: 01 August 2018, Accepted: 16 November 2018, Published online: 18 March 2019

\begin{abstract}
Three new, successful resolving agents, namely (S)-2-phenylglycinol, $(R)$-1-phenylethanaminium (R)-(1-phenylethyl) carbamate and (S)-2-hydroxy-1-phenylethanaminium (S)-(2-hydroxy-1-phenylethyl) carbamate of ibuprofen are presented. The carbamate salts are stable white crystals, they can be easily stored and handled. All salt forming resolution were performed in supercritical carbon dioxide as the only solvent. The enantioseparations were efficient (approx. $50 \%$ enantiomeric purities, > $90 \%$ yields in the crystalline phase) and robust. Unlike previous experiences with primary amine resolving agents, the diastereomeric salt formations and resolutions were competed in short times, even within one hour suggesting that the carbamates are intermediates of the salt formation reaction. Keywords
\end{abstract}

supercritical carbon dioxide, chiral, salt formation, chiral separation, carbamate, activation

\section{Introduction}

From the 1960s, importance of obtaining chiral substances in optically active from has been increasing, since the enantiomers can have different biological effects. A large share of the active pharmaceutical ingredients are chiral, thus the technologies offering enantiopure products in an economical and environmentally friendly way [1] are highly important.

Supercritical carbon dioxide is a nonpolar, non-explosive, non-toxic solvent that has a low critical temperature $\left(31.3^{\circ} \mathrm{C}\right)$ and acceptable critical pressure (7.31 MPa). Being a gas at atmospheric pressure, the carbon dioxide is completely removed from the product by depressurization, leaving a solvent-free product. The first use of supercritical fluid extraction for optical separation was presented by Fogassy et al. [2].

Ibuprofen is a widely applied pharmaceutical model compound, and also an active pharmaceutical ingredient. Ibuprofen is a non-steroid anti-inflammatory and analgesic compound, of which only the $(S)$-enantiomer is effective, and using pure $(S)$-enantiomer in therapy can be 3 times more effective than using the racemic form [3].
Resolution of ibuprofen as a model compound was carried out using organic solvent [4] and using supercritical carbon dioxide by supercritical fluid extraction $[5,6]$, by the in situ [7] and antisolvent [8] methods. Separation of ibuprofen enantiomers in organic solvents was carried out with numerous resolving agents such as: ephedrine [4], (R)-1-phenylethylamine [9], N-alkyl-D-glucamine [10] and lysine [11]. The chiral separation of ibuprofen enantiomers was also investigated by SMB (Simulated Moving Bed) [12]. As several resolutions of ibuprofen have been already developed, it is a good model substance for comparison and evaluation of novel methods.

The kinetics of the resolution of ibuprofen using $(R)-1$ phenylethylamine was investigated by Bánsághi et al. [7] by in situ method, it was found that the diastereomeric salt formation is a slow process, to achieve 0.422 selectivity, more than 100 hours of reaction time is needed at $20 \mathrm{MPa}$ and $40{ }^{\circ} \mathrm{C}$. It was also found that the primary amine $((R)-1-$ phenylethylamine) form carbamate with carbon dioxide, that can be detected if the reaction time is under 24 hours, but during longer reaction times it decomposes [13]. 
Furthermore, 1-phenylethylamine is not a very convenient resolving agent, it is a viscous liquid with a specific odor and it reacts with the $\mathrm{CO}_{2}$ content of the air as well forming a solid precipitate. Its carbamate on the other hand is a stable, white solid, which allows much more convenient storing and handling.

Salt forming resolution of ibuprofen with in situ method with $(S)$-phenylglycinol was investigated before, but Valentine did not achieve any significant enantioseparation [14]. Despite of this, according to structural similarities [15] and differential scanning calorimetry (DSC) measurements [16], $(S)$-phenylglycinol could be a suitable resolution agent.

The aim of this work is to demonstrate novel and easy-toapply salt forming resolutions with self-carbamate-salts of primary amines, namely of $(S)$-2-phenylglycinol and $(R)-1$ phenylethylamine, in carbon dioxide as the only solvent.

\section{Experimental}

\subsection{Materials}

Racemic ibuprofen (IBU) ( $\geq 98 \%$ ) was purchased from Tokyo Chemical Industry Ltd. $(S)-(+)-2$-phenylglycinol (PhG), CAS: 20989-17-7, ( $\geq 97 \%$ GC) and $(R)-(+)-1-$ phenylethylamine (PhEA), CAS: 3886-69-9, were purchased from Tokyo Chemical Industry Ltd., Carbon dioxide ( $\geq 99.5 \%$ ) was purchased from Linde Gas Hungary Co., Cltd and was used freshly distilled. Methanol was purchased from Merck Ltd.

$(R)$-1-phenylethanaminium $\quad(R)$-(1-phenylethyl)carbamate abbreviated as PhEA carbamate and $(S)$-2-hydroxy1-phenylethanaminium (S)-(2-hydroxy-1-phenylethyl)carbamate abbreviated as $\mathrm{PhG}$ carbamate are depicted on the left and right sides in Fig. 1, respectively. The PhEA carbamate and the $\mathrm{PhG}$ carbamate were produced by our high pressure vessel with pure carbon dioxide at $20 \mathrm{MPa}, 40{ }^{\circ} \mathrm{C}$ with the reaction time of $24 \mathrm{~h}$. In case of the PhEA carbamate, corresponding to previous studies pure carbamate was obtained [7]. The purity of the $\mathrm{PhG}$ carbamate was investigated by DSC measurements: the melting of the $\mathrm{PhG}$ is not detectable, thus pure $\mathrm{PhG}$ carbamate was obtained.

\subsection{Equipment}

A scheme of the high pressure crystallization apparatus used for the experiments is shown in Fig. 2.

The reactor was constructed by the Applied Chemistry Research Institute of Miskolc University, the inlet tube (3) was built in later to make the reactor suitable for crystallizing. The reactor is suitable to make reactions with carbon dioxide containing atmospheres at maximum $25 \mathrm{MPa}$

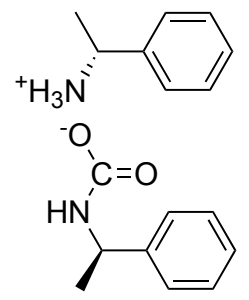

PhEA carbamate

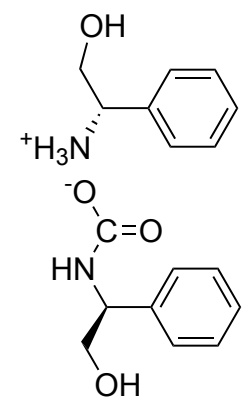

$\mathrm{PhG}$ carbamate
Fig. 1 The structure of $(R)$-1-phenylethanaminium $(R)$-(1-phenylethyl) carbamate and $(S)$-2-hydroxy-1-phenylethanaminium $(S)$-(2-hydroxy-1phenylethyl)carbamate)

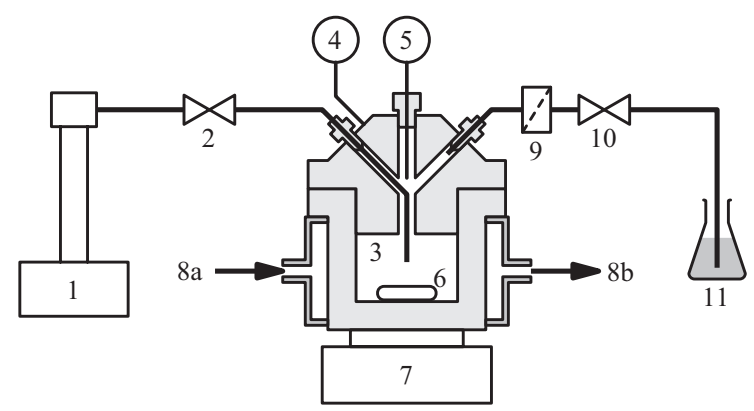

Fig. 2 reactor: carbon dioxide tank, pump and ISCO pump (1), inlet valve (2), inlet tube (3), pressure and temperature transmitter $(4,5)$, water inlet / outlet for the thermostate $(8 \mathrm{a}, 8 \mathrm{~b})$, stirrer (6), stirring motor (7), outlet valve (10), metanol trap (11), metal filter(9)

and $100{ }^{\circ} \mathrm{C}$ (the rupture disc opens at $34 \mathrm{MPa}$ ). During the investigations, three reactors were used with slightly different volumes 36.4 and $37.7 \mathrm{ml}$.

The carbon dioxide was pumped into the reactor with the ISCO 260D pump through the valve (2) and the inlet tube (3). This tube is needed to ensure the carbon dioxide to flow to the bottom of the reactor, thus it cannot happen that during the washing phase not the complete volume of the reactor is washed, this would decrease the effectivity of washing.

The temperature transmitter (5) is connected to a computer in which the measured data is recorded. This way, the temperature data can be monitored any time for the entire reaction time, even days. The pressure transmitter (4) is also connected to the data recording computer and the pressure is displayed on a digital display as well.

The stirrer magnet (6) is driven by the stirrer motor (7) with up to $1100 \mathrm{rpm}$. Depressurization is possible through the outlet valve (10). In front of the valve there is a metal filter (9) to prevent crystals from flowing out of the reactor.

After washing, during depressurization the carbon dioxide was flown through trap with $40 \mathrm{ml}$ methanol. This way, the extract could be collected. 
The reactor's temperature was set by tempered water flown in the jacket of the reactor.

\subsection{Methods}

For all experiments $0.200 \mathrm{~g}$ IBU was used with 0.5 molar equivalent resolving agent which is $0.0694 \mathrm{~g}$ in case of using PhEA carbamate and $0.0665 \mathrm{~g}$ in case of $\mathrm{PhG}$ carbamate.

The IBU and the resolving agent were placed into the bottom of the reactor, then the reactor was closed and stirring was started at $750 \mathrm{rpm}$. The reactor was pressurized with pure carbon dioxide in 10-15 minutes. After reaching the desired pressure, the reaction mixture was continuously stirred until a pre-set time at constant pressure and temperature. Once the pre-set time elapsed, the reactor was washed with a calculated amount of $\mathrm{CO}_{2}$ at constant pressure, temperature and stirring. The carbon dioxide flow rate was 1.5 $\mathrm{ml} / \mathrm{min}$ and the extraction took about an hour. The extract was collected in a methanol trap. After the depressurization and the opening the reactor, the raffinate was collected in solid form. To ensure full material recovery, the part of the raffinate that could not be collected was washed out by methanol. Mass of extract and raffinate were calculated after the evaporation of the solvent. Total mass recoveries (cumulative mass of the extract and the raffinate compared to the mass of the reactants used) were excellent (95-100 \%). The values above one caused by small rubber filings.

\subsection{Determination of enantiomeric purity using capillary electrophoresis (CE)}

Capillary electrophoresis measurements were carried out by Cyclolab Ltd. (Budapest, Hungary) using an Agilent Technologies (Waldbronn, Germany) ${ }^{3 \mathrm{D}} \mathrm{CE}$ apparatus, equipped with a diode array detector. All measurements were carried out using a silica capillary with untreated surface, with a total length of $58.5 \mathrm{~cm}$, of which $50 \mathrm{~cm}$ was before the detector. The internal diameter of the capillary was $50 \mu \mathrm{m}$. The capillary was thermostated at $25^{\circ} \mathrm{C}$ during measurements, with $20 \mathrm{kV}$ voltage set between the electrodes. Analysis time was $12 \mathrm{~min}$ per sample. The separated components were detected at a wavelength of 200 $\mathrm{nm}$. The continuously flowing electrolyte solution was a $\mathrm{pH}$ 4.5 Britton-Robinson buffer, with TRIMEB (permethylated- $\beta$-cyclodextrin prepared by Cyclolab Ltd.) as a chiral selector in $12.5 \mathrm{mM}$ concentration. During evaluation of the electrophorograms, the percentage ratio of the peaks corresponding to the separated enantiomers compared to the cumulative area of all peaks was calculated, while the diastereomeric excess and enantiomeric excess were calculated.

\subsection{Powder X-ray diffraction}

Powder X-ray diffractograms were obtained using a PANalytical X'Pert Pro MPD (Almelo, The Netherlands) diffractometer, equipped with an $X^{\prime}$ celerator detector in $\Theta-\Theta$ arrangement. The radiation source was an X-ray tube with a $\mathrm{Cu}$ anode, analyses were carried out at the $\mathrm{K} \alpha$ wavelength of $\mathrm{Cu}(1.5408 \AA)$, applying $40 \mathrm{kV}$ voltage and $30 \mathrm{~mA}$ current. The $\mathrm{K} \beta$ wavelength of $\mathrm{Cu}$ was filtered out using a nickel foil. Scanned diffraction angles angles were varied between $4^{\circ}$ and $42^{\circ}$. The measurement time was chosen as $10 \mathrm{~min}$ in order to improve signal / noise ratio.

\subsection{Calculation}

The calculation methods are consistent with the earlier work of Bánsághi et al. [7] to ensure comparability.

The $F$ parameter that indicates the resolution efficiency was calculated by Eq. (1)

$$
F=\left(|e e| \cdot Y_{e}+|d e| \cdot Y_{r}\right) / 2 \text {. }
$$

In this formula (Eq. (1)), $Y$ denotes the theoretical yield, $e$ and $r$ subscripts denote extract and raffinate, ee and de denote enantiomeric purities of the extract and the raffinate, respectively. $F$-parameter values are in the range of $0-1$. Please note, that theoretical yield is the mass of recovered material in the given fraction (i.e. extract or raffinate) relative to the theoretical mass of the given fraction assuming full conversion of the reaction and that the residence time distribution in the extraction step is according an ideal continuously stirred tank reactor (CSTR) model [7].

\section{Results and discussion}

The salt forming resolution of IBU with PhEA carbamate was investigated at $40{ }^{\circ} \mathrm{C}$, at pressures $10-15-20 \mathrm{MPa}$ and at $50{ }^{\circ} \mathrm{C}$ and $15 \mathrm{MPa}$. Fig. 3 shows the evolution of the $F$ parameter values with time. The salt forming resolution is efficient with PhEA carbamate and the operational parameters do not have any significant effects. The reaction reaches an equilibrium within 24 hours in all cases and there is a similar final resolution efficiencies of $F \sim 0.47$.

Comparing the results with using the PhEA as resolving agent under the same reaction conditions [7], the equilibrium is much faster achieved $(168 \mathrm{~h} \rightarrow 24 \mathrm{~h})$ in case of using the carbamate than using the primary amine itself.

Interestingly, the reaction starting from the PhEA carbamate seems to be the slowest at $20 \mathrm{MPa}$, while Bánsághi et al. [7] reported that increasing pressure accelerated the reaction when PhEA as primary amine was directly applied as resolving agent. The reason is supposed to be that the PhEA 


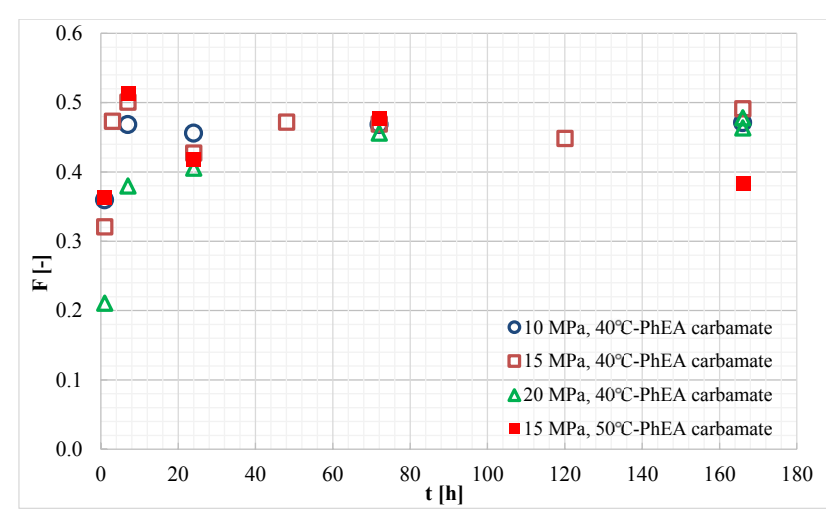

Fig. 3 Resolution of IBU with PhEA carbamate.

carbamate salt is an intermediate of the diastereomeric salt formation reaction. The first step, formation of PhEA self-carbamate salt from $\mathrm{PhEA}$ is faster at higher pressures. It is a carbon dioxide fixation reaction involving precipitation (volume reduction), thus not only the increasing $\mathrm{CO}_{2}$ excess by pressure, but the pressure itself. Those are both supposed to increase the reaction rates. The seconds step, the decomposition of the self-carbamate salt to form the diastereomeric salt with ibuprofen however, results in $\mathrm{CO}_{2}$ as byproduct, thus it should not be favored at higher pressures.

The salt forming resolutions stating from the primary amine and from its carbamate salt result in similar $F$ values at the equilibrium, and the raffinates have similar crystal structures according to the XRD patterns (Fig. 4). The solid, crystalline raffinate do not contain significant amount $\mathrm{PhEA}$ carbamate, as its representative peak at $6^{\circ}[13]$ is not visible in any of the diffractograms. Comparing the XRD patterns to diastereomeric salt references (atmospherically prepared and earlier obtained) peak positions and intensity ratios are similar suggesting similar solid phases.

Diastereomeric excess values in equilibrium starting from $\mathrm{PhEA}$ and its carbamate are similar as well, $50 \% \pm$ $6 \%$. Furthermore, the carbamate based reaction system is more robust. It is not sensitive to the varied process pressure and temperature.

Resolution of IBU by in situ diastereomeric salt formation with $\mathrm{PhG}$ resolving agent in pure carbon dioxide solvent was investigated at $42.5^{\circ} \mathrm{C}$ at pressures 10-15-20 MPa and at $15 \mathrm{MPa}$ at different temperatures $\left(35-42.5-50{ }^{\circ} \mathrm{C}\right)$ as well. The formation of $\mathrm{PhG}$ carbamate is detectable on the XRD diffractograms at during short reaction times $(t<24 \mathrm{~h})$ like in case of using PhEA as resolving agent. However, in this salt forming resolution neither the pressure nor the temperature influenced significantly the reaction rate or the resolution efficiency. Thus resolution with

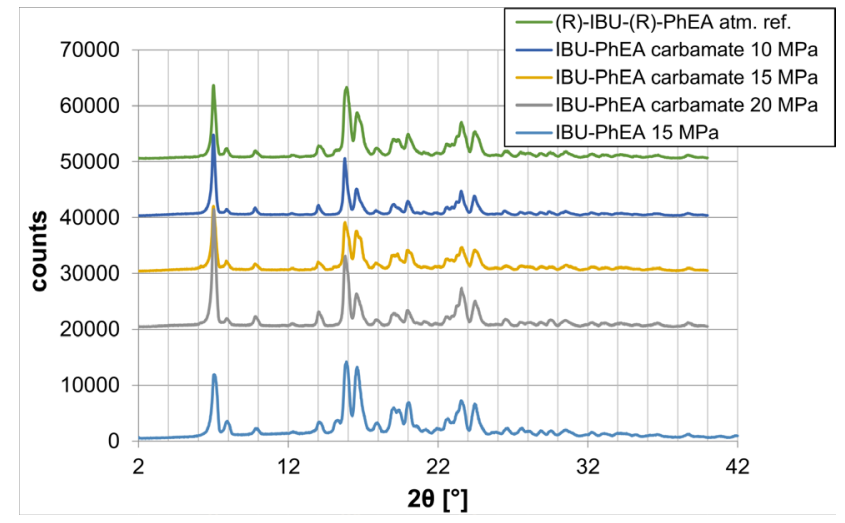

Fig. 4 Diffractograms of raffinates at $40{ }^{\circ} \mathrm{C}$. The green line is an atmospheric reference without $\mathrm{CO}_{2}$.

Table 1 The detailed data of measurement results on Fig. 3.

\begin{tabular}{|c|c|c|c|c|c|c|c|c|}
\hline $\begin{array}{l}P \\
{[\mathrm{MPa}]}\end{array}$ & $\begin{array}{c}T \\
{\left[{ }^{\circ} \mathrm{C}\right]}\end{array}$ & $t[\mathrm{~h}]$ & $\begin{array}{l}d e \\
{[-]}\end{array}$ & $\begin{array}{l}e e \\
{[-]}\end{array}$ & $\begin{array}{l}Y_{r} \\
{[-]}\end{array}$ & $\begin{array}{l}Y_{e} \\
{[-]}\end{array}$ & $\begin{array}{l}F \\
{[-]}\end{array}$ & $\begin{array}{c}\text { recovery } \\
{[-]}\end{array}$ \\
\hline 10 & 40 & 1 & 0.40 & 0.30 & 0.90 & 1.21 & 0.36 & 1.00 \\
\hline 10 & 40 & 7 & 0.58 & 0.39 & 0.92 & 1.03 & 0.47 & 0.96 \\
\hline 10 & 40 & 24 & 0.47 & 0.53 & 0.94 & 0.88 & 0.46 & 0.92 \\
\hline 10 & 40 & 72 & 0.49 & 0.58 & 0.96 & 0.81 & 0.47 & 0.91 \\
\hline 10 & 40 & 166 & 0.46 & 0.63 & 0.97 & 0.79 & 0.47 & 0.91 \\
\hline 15 & 40 & 1 & 0.46 & 0.20 & 0.76 & 1.44 & 0.32 & 0.98 \\
\hline 15 & 40 & 3 & 0.52 & 0.37 & 0.88 & 1.34 & 0.47 & 1.04 \\
\hline 15 & 40 & 7 & 0.50 & 0.54 & 0.98 & 0.95 & 0.50 & 0.97 \\
\hline 15 & 40 & 24 & 0.54 & 0.39 & 0.97 & 0.83 & 0.43 & 0.93 \\
\hline 15 & 40 & 48 & 0.52 & 0.56 & 0.91 & 0.85 & 0.47 & 0.89 \\
\hline 15 & 40 & 72 & 0.50 & 0.57 & 0.93 & 0.83 & 0.47 & 0.90 \\
\hline 15 & 40 & 120 & 0.51 & 0.54 & 1.04 & 0.67 & 0.45 & 0.92 \\
\hline 15 & 40 & 166 & 0.51 & 0.57 & 1.10 & 0.74 & 0.49 & 0.98 \\
\hline 20 & 40 & 1 & 0.27 & 0.14 & 0.83 & 1.38 & 0.21 & 1.01 \\
\hline 20 & 40 & 7 & 0.38 & 0.35 & 0.90 & 1.18 & 0.38 & 0.99 \\
\hline 20 & 40 & 24 & 0.34 & 0.50 & 0.88 & 1.03 & 0.41 & 0.93 \\
\hline 20 & 40 & 72 & 0.43 & 0.54 & 0.93 & 0.95 & 0.46 & 0.94 \\
\hline 20 & 40 & 166 & 0.55 & 0.51 & 1.02 & 0.72 & 0.46 & 0.92 \\
\hline 20 & 40 & 166 & 0.55 & 0.55 & 1.06 & 0.69 & 0.48 & 0.94 \\
\hline 15 & 50 & 1 & 0.51 & 0.25 & 0.89 & 1.12 & 0.36 & 0.97 \\
\hline 15 & 50 & 7 & 0.42 & 0.62 & 0.92 & 1.04 & 0.51 & 0.96 \\
\hline 15 & 50 & 24 & 0.39 & 0.58 & 0.97 & 0.79 & 0.42 & 0.92 \\
\hline 15 & 50 & 72 & 0.51 & 0.55 & 0.96 & 0.84 & 0.48 & 0.92 \\
\hline 15 & 50 & 166 & 0.46 & 0.39 & 1.07 & 0.70 & 0.38 & 0.95 \\
\hline
\end{tabular}

the $\mathrm{PhG}$ carbamate resolving agent was investigated at 15 $\mathrm{MPa}$ and $42.5^{\circ} \mathrm{C}$ only.

Fig. 5 shows the time scale results of the salt forming resolution of IBU with $\mathrm{PhG}$ and it's carbamate. 24 hours are needed to reach the equilibrium, above this reaction time, $F$ value is constant. 
Table 2 The detailed data of measurement results on Fig. 5.

\begin{tabular}{lcccccccc}
\hline$P$ & $T$ & $t[\mathrm{~h}]$ & $\begin{array}{c}d e \\
{[-]}\end{array}$ & $\begin{array}{c}e e \\
{[-]}\end{array}$ & $\begin{array}{c}Y_{r} \\
{[-]}\end{array}$ & $\begin{array}{c}Y_{e} \\
{[-]}\end{array}$ & $\begin{array}{c}F \\
{[-]}\end{array}$ & $\begin{array}{c}\text { recovery } \\
{[-]}\end{array}$ \\
\hline 10 & 42.5 & 1 & 0.29 & 0.35 & 1.07 & 0.96 & 0.32 & 1.03 \\
10 & 42.5 & 24 & 0.43 & 0.48 & 1.05 & 0.86 & 0.43 & 0.99 \\
10 & 42.5 & 72 & 0.50 & 0.46 & 1.07 & 0.84 & 0.46 & 0.99 \\
15 & 42.5 & 1 & 0.39 & 0.23 & 0.78 & 1.48 & 0.32 & 1.00 \\
15 & 42.5 & 1 & 0.22 & 0.42 & 0.88 & 1.12 & 0.33 & 0.96 \\
15 & 42.5 & 24 & 0.56 & 0.42 & 0.84 & 1.23 & 0.49 & 0.97 \\
15 & 42.5 & 24 & 0.49 & 0.45 & 0.86 & 1.26 & 0.49 & 0.98 \\
15 & 42.5 & 72 & 0.53 & 0.50 & 0.93 & 1.10 & 0.52 & 0.98 \\
15 & 42.5 & 72 & 0.51 & 0.55 & 0.93 & 1.13 & 0.55 & 1.00 \\
15 & 42.5 & 166 & 0.50 & 0.50 & 0.93 & 1.08 & 0.51 & 0.98 \\
20 & 42.5 & 1 & 0.36 & 0.32 & 0.90 & 1.37 & 0.38 & 1.05 \\
20 & 42.5 & 24 & 0.54 & 0.37 & 0.88 & 1.29 & 0.47 & 1.01 \\
20 & 42.5 & 72 & 0.45 & 0.49 & 1.00 & 1.20 & 0.52 & 1.06 \\
20 & 42.5 & 166 & 0.54 & 0.47 & 0.93 & 1.13 & 0.51 & 0.99 \\
15 & 42.5 & 168 & 0.48 & 0.46 & 0.90 & 1.04 & 0.45 & 0.94 \\
15 & 42.5 & 120 & 0.51 & 0.49 & 0.97 & 1.10 & 0.52 & 1.02 \\
15 & 42.5 & 144 & 0.49 & 0.45 & 0.88 & 1.23 & 0.49 & 0.99 \\
15 & 42.5 & 1 & 0.53 & 0.43 & 0.89 & 1.16 & 0.49 & 0.98 \\
15 & 42.5 & 144 & 0.48 & 0.49 & 0.92 & 0.95 & 0.45 & 0.93 \\
15 & 42.5 & 23 & 0.54 & 0.53 & 0.91 & 1.29 & 0.59 & 1.03 \\
15 & 42.5 & 96 & 0.46 & 0.46 & 0.88 & 1.17 & 0.47 & 0.97 \\
15 & 42.5 & 73 & 0.49 & 0.51 & 0.98 & 0.98 & 0.49 & 0.98 \\
\hline & & & & & & & &
\end{tabular}

During resolution with $\mathrm{PhG}$ carbamate reaching the equilibrium is also faster, it was achieved in one hour. The achieved resolution is similar $F=0.5$, slightly better than using PhEA resolving agent. Both $\mathrm{PhG}$ and $\mathrm{PhG}$ carbamate employing salt forming resolutions result in similar $F$ values at the equilibrium, and the raffinates have similar crystal structures according to the XRD patterns (Fig. 6). The yield and diastereomeric excess values of the raffinates in equilibrium are $93 \% \pm 5 \%$ and $51 \% \pm 4 \%$, respectively.

Further investigations are required to understand the accelerated reaction rates when the self-carbamate-salts of the primary amines are used. Taking into account that the equilibrium resolution efficiencies and diastereomeric purities are the same with the PhEA and its self-carbamate-salt and also with PhG and its self-carbamate-salt, one may assume that the carbamate is already an intermediate of the reaction. It is also possible, that the carbamates are somehow activated thus the activation energy of the diastereomeric salt formation is decreased when a carbamate is used. Sparingly, but similar observations can be found in the literature already, which makes us believe, that the self-carbamate-salts might have yet undiscovered

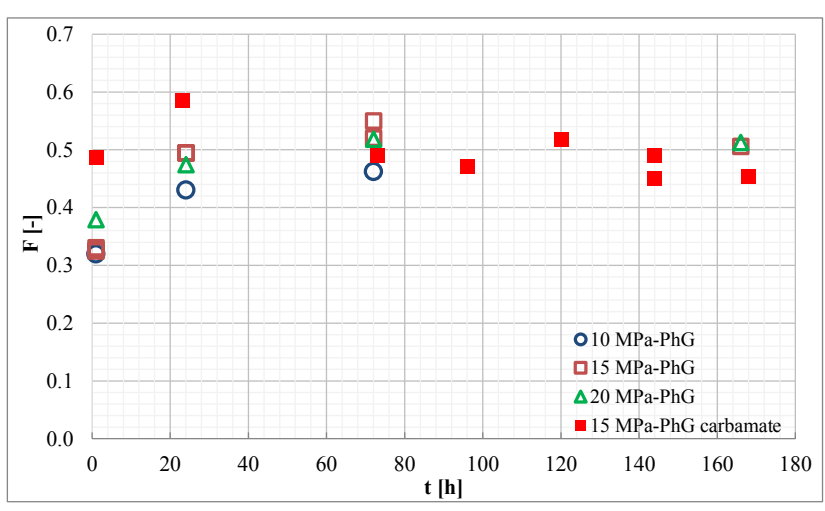

Fig. 5 Resolution of IBU with PhG and PhG carbamate.

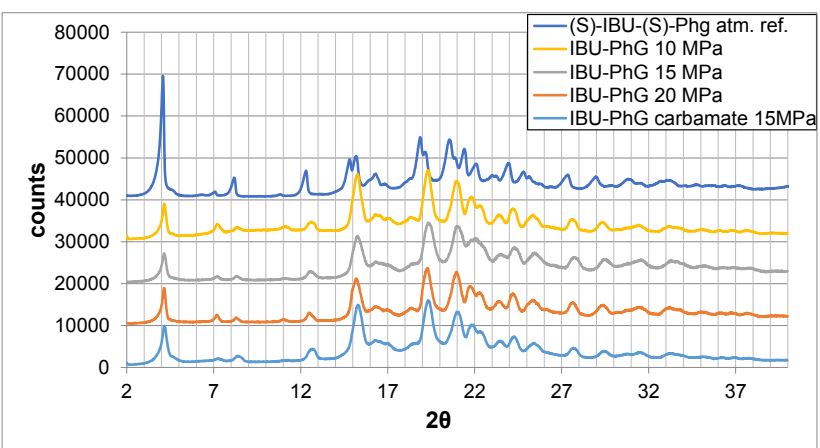

Fig. 6 Diffractograms of raffinates at $42.5^{\circ} \mathrm{C}$. The blue line is an atmospheric reference without $\mathrm{CO}_{2}$.

potentials. Nimura and coworkers published some papers in the 1980's on the analytical applications of activated carbamates [17-19] for separation of amines. Tilborg et al. [20] suggested, that natural carbonization and self-carbamate salt formation might be much common in amine involving reactions and catalysis than it was previously supposed. These forms might be more reactive than the amines themselves, which is in agreement with our experiences.

\section{Conclusion}

Three new, successful resolving agents, namely $(S)$-2-phenylglycinol, $\quad(R)$-1-phenylethanaminium $(R)$-(1-phenylethyl) carbamate and (S)-2-hydroxy-1phenylethanaminium (S)-(2-hydroxy-1-phenylethyl) carbamate of ibuprofen are presented in the paper. All salt forming resolutions are efficient (appr. $50 \%$ enantiomeric excess, $>90 \%$ yields in the crystalline phase) and robust. The mass recovery was high, $95-100 \%$ in most cases. The pressure and temperature, in the studied ranges, do not influence the salt forming resolution significantly. The salt forming resolution with the self-carbamate-salts of the primary amines achieve the same equilibrium in a shorter time than with the corresponding 
amine suggesting an activation of the amine with its reaction with carbon dioxide forming the self-carbamate-salt. Using $\mathrm{PhG}$ and its derivative results in a slightly higher $F$ value $(F=0.5)$ than PhEA and its derivative $(F=0.47)$.

\section{References}

[1] Murakami, H. "From Racemates to Single Enantiomers - Chiral Synthetic Drugs over the last 20 Years", In: Sakai, K., Hirayama, N., Tamura, R. (eds.) Novel Optical Resolution Technologies, Topics in Current Chemistry, Springer, Berlin, Heidelberg, pp. 273-299, 2007.

https://doi.org/10.1007/128 2006072

[2] Fogassy, E., Ács, M., Szili, T., Simándi, B., Sawinsky, J. "Molecular chiral recognition in supercritical solvents", Tetrahedron Letters, 35(2), pp. 257-260, 1994. https://doi.org/10.1016/S0040-4039(00)76525-7

[3] Adams, S. S., Bresloff, P., Mason, C. G. "Pharmacological differences between the optical isomers of ibuprofen: evidence for metabolic inversion of the (-)-isomer", Journal of Pharmacy and Pharmacology, 28(3), pp. 256-257, 1976. https://doi.org/10.1111/j.2042-7158.1976.tb04144.x

[4] Manimaran, T., Stahly, G. P. "Optical purification of profen drugs", Tetrahedron: Asymmetry, 4(8), pp. 1949-1954, 1993. https://doi.org/10.1016/S0957-4166(00)80436-X

[5] Molnár, P., Székely, E., Simándi, B., Keszei, S., Lovász, J., Fogassy, E. "Enantioseparation of ibuprofen by supercritical fluid extraction", The Journal of Supercritical Fluids, 37(3), pp. 384$389,2006$.

https://doi.org/10.1016/j.supflu.2005.10.009

[6] Keszei, S., Simandi, B., Fogassy, E., Sawinsky, J., Niklós, C., Lovas, R. "Resolution of ibuprofen and cis-chrysanthemic acid by supercritical fluid extraction", Process Technology Proceedings, 12(C), pp. 393-398, 1996. https://doi.org/10.1016/S0921-8610(96)80068-9

[7] Bánsághi, G., Székely, E., Sevillano, D. M., Juvancz, Z., Simándi, B. "Diastereomer salt formation of ibuprofen in supercritical carbon dioxide", Journal of Supercritical Fluids, 69, pp. 113-116, 2012. https://doi.org/10.1016/j.supflu.2012.05.016

[8] Lőrincz, L., Bánsághi, G., Zsemberi, M., de Simón Brezmes, S., Szilágyi, I. M., Madarász, J., Sohajda, T., Székely, E. "Diastereomeric salt precipitation based resolution of ibuprofen by gas antisolvent method", The Journal of Supercritical Fluids, 118, pp. 48-53, 2016. https://doi.org/10.1016/j.supflu.2016.07.021

[9] Manimaran, T., Impastato, F. J., Ethyl Corporation, "Preparation of Optically Active Aliphatic Carboxylic Acids", USA, US5015764A, 1991.

[10] Schloemer, G. C., Lodewijk, E., Withers, G., P. "Resolution of ibuprofen", USA, US5621140A, 1994.

[11] Tung, H.-H., Waterson, S., Reynolds, S. D. "Formation and Resolution of Ibuprofen Lysinate", USA, US4994604A, 1991. [online] Available at : http://www.google.com/patents/US4994604 [Accessed: 24 May 2017]

\section{Acknowledgement}

Our research was supported by the Hungarian Scientific Research Fund, grant number K108979 and PD-109129 projects.

[12] Park, J. S., Kim, W.-S., Kim, J. M., Kim, I.-H. "Ibuprofen Racemate Separation by Simulated Moving Bed", Journal of Chemical Engineering of Japan, 41(7), pp. 624-626, 2008. https://doi.org/10.1252/jcej.07WE102

[13] Madarász, J., Székely, E., Halász, J., Bánsághi, G., Varga, D., Simándi, B., Pokol, G. "Ammonium carbamate type self-derivative salts of $(R-)$ - and racemic $\alpha$-methylbenzylamine", Journal of Thermal Analysis and Calorimetry, 111(1), pp. 567-574, 2013. https://doi.org/10.1007/s10973-011-2174-5

[14] Valentine, R. "Enantiomeric Resolution of Racemic Ibuprofen in Supercritical Carbon Dioxide Using a Chiral Resolving Agent", Doctoral Dissertation, University of Pittsburgh, USA, 2002. [online] Available at: http://d-scholarship.pitt.edu/id/eprint/6600 [Accessed: 24 May 2017]

[15] Faigl, F., Fogassy, E., Nógrádi, M., Pálovics, E., Schindler, J. "Strategies in optical resolution: a practical guide", Tetrahedron: Asymmetry, 19(5), pp. 519-536, 2008. https://doi.org/10.1016/j.tetasy.2008.02.004

[16] Ebbers, E. J., Plum, B. J. M., Ariaans, G. J. A., Kaptein, B., Broxterman, Q. B., Bruggink, A., Zwanenburg, B. "New resolving bases for ibuprofen and mandelic acid: qualification by binary phase diagrams", Tetrahedron: Asymmetry, 8(24), pp. 4047-4057, 1997. https://doi.org/10.1016/S0957-4166(97)00557-0

[17] Brimer, L., Dalgaard, L. "Cyanogenic Glycosides and Cyanohydrins in Plant Tissues: Qualitative and Quantitative Determination by Enzymatic Post-column Cleavage and Electrochemical Detection, after Separation by High-performance Liquid Chromatography", Journal of Chromatography A, 303, pp. 77-88, 1984. https://doi.org/10.1016/S0021-9673(01)96047-9

[18] Iwaki, K., Yoshida, S., Nimura, N., Kinoshita, T., Takeda, K., Ogura, H. "Activated Carbamate Reagent as Chiral Derivatizing Agent for Liquid Chromatographic Optical Resolution of Enantiomeric Amino Compounds", Chromatographia, 23(12), pp. 899-902, 1987.

https://doi.org/10.1007/BF02261468

[19] Nimura, N., Iwaki, K., Kinoshita, T., Takeda, K., Ogura, H. "Activated Carbamate Reagent as Derivatizing Agent for Amino Compounds in High-Performance Liquid Chromatography", Analytical Chemistry, 58(12), pp. 2372-2375, 1986. https://doi.org/10.1021/ac00125a005

[20] Tilborg, A., Lanners, S., Norberg, B., Wouters, J. "Solid-StateTrapped Reactive Ammonium Carbamate Self-Derivative Salts of Prolinamide", ChemistryOpen, 2(5-6), pp. 194-199, 2013. https://doi.org/10.1002/open.201300025 